\title{
How is the language of imagery in lyric's of Amir Khosro Dehlavi
}

\author{
Javad Farasati ${ }^{1}$, Mir Jalaloddin Kazzazi ${ }^{2}$
}

Received:20.08.2015

\author{
Revised:25.09.2015
}

Accepted: 30.10.2015

\begin{abstract}
Whenever there is an amazing resurrection in a nation's language which leads to create an artistic masterpiece in that language, it is called literature. For this reason, we can differentiate between literary language and daily or spoken language. Writers and literates from various countries will often try to utilize a literary approach in order to make their utterances and poems more attractive and popular through the use of written imagery and artily, illustratively capturing the emotion of the written words. Amir Khosro Dehlavi; who is a well-known Hindi poet, has mastered the illustrative nature of the Farsi language to compose his euphonious lyric poems. In reviewing his work, we will try to evaluate the context of his poems and the way he has used imaginary and artily language structures, consisting of words, combinations, sentences and phrases in his lyrics, as well as evaluating the way he introduces an imagery approach to his poems.
\end{abstract}

Key words: Resurrection, Amir Khosro Dehlavi, Context, Imagery Language, language structures.

\section{Introduction}

In this inquiry we will discuss language structures and context which are the basis of the artistic imageries of Amir Khosro's lyrics. Amir Khosro can be assumed to be an ingenious and capable composer in terms of utilizing different language structures to create fancied lyrics. This is why syntax territory in text is a category that can encompass multifarious language structures. Additionally, historically speaking, aesthetics scholars have examined the role and influence of these structures in creation of literary masterpieces and knowledge such as rhetoric has been the result of their efforts. Dr Shafiee Kadkaniis quoted as saying "According to the greatest theorist of rhetoric of Iran and Islam; Abdolghaaher Jarjaani's regard, eloquence and impact is limited in the realm of syntactic structures of language(82-1991), and calls semantics.(ShafieeKadkani3:1996).Siroos Shamisa also says" literary language in general is visual languageand scrutinizing the images is the subject of rhetoric. So one can say rhetoric is the grammar of literature"(Shamisa 17:2002).

In the syntax of literary and artistic works, grammatical and linguistic structures are used to illustrate the emotional context of literary art creators, and as a result of this words, phrases and sentences are used to transfer the emotions of writer to readers. Of course we should consider

\section{Author's Address}

${ }^{1}$ Department of Faculty of Language and Literature, Science and Research Branch, Islamic Azad University, Tehran, Iran.

${ }^{2}$ Department of Faculty of Persian Language and Literature and Foreign Languages, Allameh Tabatabaee University of Tehran, Iran .

Email: mjkazzazi@yahoo.es. that diverse language structures do not show ebullient emotions of penman and it's based upon the philosophical and psychological inferences made by both the writer and reader. Artistic creation and concinnity in the text should written in such a way that it stimulates the reader's internal emotions. The creators of artistic works do not have the same opinion about the same work, because according to different conditions, times and places, their emotions will influence their interpretation in different ways. In Hermenotic's critic school, the main issue is reader's personal impressions about literary works and because of this, followers of this school do not consider one unique nor specific concept. Gadamer says "Hermenotic's idea is uncomplicated; it says I don't need the last word it's unnecessary"(Ahmadi, 1991; 25). Accordingly, we should say the structure of literary text in terms of function and effect is not like scientific or research prose which have the same message for all readers. Rather language structures like words, phrases and sentences in literary works go beyond the literal and transfer different emotions and feelings to readers according to the time and place. With this regard we will discuss divers linguistic and rhetoric structures in Amir Khosro's lyrics.

\section{Literature review}

Notwithstanding many efforts by providers of Amir Khosro's poetry, when we scrutinize the text of those versions we will realize they have lost out to access a considerable and weighty text for researchers to use it in their studies, and there are significant problems in the case of language structures, grammatical, rhetoric and versification in lyrics of this well known Indian poet. Hence less 
research has been done about his lyrics which possess a lot of artistic imageries. Accordingly, first of all we should do a scientific and critical editing on his lyrics, by which we will have a source which is flawless andwithout any complexity or in sufficiency, and in doing so, we can conduct significant research about Amir Khosro's works. Nonetheless we have tried our best to investigate a small portion of visual language structures of his poetry in this inquiry.

\section{Materials and Methods}

Imagery language structures in Amir Khosro Dehlavi's lyrics

1. Allegory:Different kinds of allegory in Amir Khosro's poetry either counterbalance, giving example or proverbs that are artistic and effective in transferring emotions and excitement to readers in a skillful and artful manner.

If Khosro feels sorrow for you, he just wails in anguish town criers will be paid after their hustle.(Amir Khosro Dehlavi:1964:68)

Khosro can't stop crying because of the deep pricking pain yes the burning earthenware will boil water.(same:74)

When my antagonist lost his control then belittled me dog will stick his tongue out whit the sun's heat. ( same :103)

Oh Khosro how much you want to vaunt drums loud voice shows that it's empty inside. ( same :264)

My heart shows it's sadness through my eyes but stayed in my eyelashes like someone who tries to escape from rain but find himself under the downpipe .(same:320)

Oh Khosro those who try to consult coquettes they clean ewe's blood fromponiard (same:798)

2.Allusion: Among other imageries in Amir Khosro's works we can mention very elegant and rare allusions which are of his rhetorical inventions which lead to create new senses in his works. But we should not forget that the main subject about allusion is it's latency, unfamiliarity and novelty, and at the same time they are associated with other aesthetics factors such as; vagueness, triviality and being two dimensional. Therefore allusion is the reflection of artist's spirit via his language imagery in reader's mind. And verily Amir Khosro Dehlavi has done so masterly for this purpose:

What do they know about affliction of being away from beloved one those who never stay awake to think about their loved one.(same:17)
My lover kissed my lips and made me speechless my lips became like a sealed letter I couldn't say anything else.(same:78)

Your face is like a rose in my eyes with my inside ardor I will extract its rosewater.(same:107) Each night your illusion makes my heart soundless how can I tolerate it till next morning.(same:1195)

3.Metaphor: There are significant metaphors in Amir Khosro's lyrics which demonstrate his high potency in creating poetic contents and themes, of which there are two types:

\section{A:Nominal composition(Eloquent metaphor):}

I am disabled to escape from this love which I am stuck in it Oh my God don't let me alone and helpless.(same:19)

Oh Khosro your week body in life's garden Is like a bird which escape from it's cage.(same:46)

I cannot lead my tolerance force anymore because I didn't see your beautiful eyes today.(same:45)

Now all the city know from my sense that I can order the tolerance(I can not seal it's order).(same:47)

In aesthetics perspective these verses can have these traits:

1- $\quad$ Amir Khosro has attained a kind of artistic brevity.

2- He has drawn novel paintings.

3- Amir Khosro has used these metaphors with other rhetoric elements to strengthen their impression.

\section{B: Sentence (Extended metaphor):}

Your wine colored lips made me dazed like meat on barbecue my eyes are weeping blood. ( same : 41 )

When I think about your face and your hair my eyes seemed half sun and half cloud.( same : 41 )

It seems your cloths are all golden and your hair's step brother is light air .(same:49)

Oh Khosro don't express your wisdom where a wise man is being treated like a young student .(same:69)

That sweat which is on your face makes your face like a rosewater which covered a rose.(same:91)

Your face is succulent like a red flower but face is sallow like saffron (you are cheerful but I am sad).(sdame:123)

Even if sorrow has built up a mansion in my heart I can destroy it by drinking wine and getting drunk (same:401)

As it is clear and visible most of the given metaphors are like stable colorful pictures, however sometimes they become active due to the 
kind of verb used for them specially in implicit metaphor.

4:Trope: trope is one of the most widely used imageries in Amir Khosro's poetry which can be found in some types:

\section{A: Word (noun)}

Your face is beautiful like jasmine and when your hair spread on it even the sun bow infront of your beauty. (same:281)

B:Nominal composition (noun and adjective, further and possessed, stipulated trope, descriptive trope and recognition)

Oh me gorgeous lover now nightingale is singing in garden it's time for you to be there like a cedar (lover is beautiful and high grown like a cedar).(same:60)

Oh friend don't build up your home on this damp place no one build house on flood's passage.

(same:47)

Oh slater no problem if you obsrtuct me

eyes of wisedom are opened (I'm

careful).(same:54)

When your black hair threw a lasso on deer it's bag of musk was closed by your hair strand.(same:391)

C: Sentence (highlighting and recognition= trope in verb) this kind of trope, is the most widely used imagery picture in Amir Khosro's lyrics:

You are walking around and I'm watching your flirting who gave you this beauty and coquetry like a cedar.(same:33)

If my tears are always trill out the reason is my eyes have been always wandering to find you.(same:46)

Your eyes like narcissus are bright if I can look at them all of chagrins will vanish.(same:47)

I felt in love with your eye borrows that's why my poor heart broke In two parts.(same:49)

Your eyes oh lover are full of seditions there are a lot of pests beneath your lips (your love put me in danger).(same:99)

The rosary decorated itself with colorful roses and pansies turn the rosary's corners into blue.(same:288)

When wind traverse among your hair it will cause chains of insanity to wave.(same:297)

My patience fled away again now where should find that tourist(my patience).(same:319)

Just today control your inner turmoil try to rely on yourself in days of loneliness.(same;332)

Lover's nights do niot always end in cheerful morning because there is always grief of love in his dreams.(same:575)
Amir Khosro has used tropes in his poetry at a sentence level. His poetry tropes have the following characteristics:

1- $\quad$ They cause the reader to think critically and this way they will be surprised and happy after recovering the writers spirit in expressing those words.

2- $\quad$ They have presentational and figurative aspect and create active and dynamic pictures.

3- $\quad$ They lead to new content creations and extend linguistic concepts.

Amir Khosro has used other image creation and aesthetics tools, such as paradox and opacity, but their frequency is too inconsiderable and pale:

\section{Paradox:}

Is there any lovelorn to dance with my moaning because my moan is like sound of harp. (same;103) Opacity:

Roses are such became dried due to your distance so there isn't even a drop of rosewater from all the roses together (same:117)

\section{Results and Discussion}

Last but not least, linguistic and grammar structures which are related to context and tenor of speech, in literary language are a tool for showing the composer's emotions and play an artistic role. Venerable literary language creates pictures, has melody, has coquetry and dances around to show itself. In external context of literary language, nouns, adjectives, adverbs and verbs play an imagery role and show the ebullient emotions of writer. For instance; nouns and specificallyproper nouns, as well as substantive (concrete) nouns can act as a manifestation of spirit and emotions and in other words make a connection between inner and outer world of writer and show it via using a name. It's here in this context that most of the metaphors, tropes, allusions, opacities and symbols have been created. Amazingly when nouns are used in the form of noun compositions, they can manifest great scenes with emotional roles, so that the reader can even feel and perceive their color, smell, taste, shape and so on. Another structure which most of recognitions and highlighting in literary language occur through them are verbs; which illustrate pictures and imageries in a dynamic sense, like a movie. Adjectives also play their roles in recognition and highlighting artistic scenes, in literary language they are the realization tools of language which act in frame of senses such as smell, shape and taste. On the other hand, adverbs also play their role in creating conceptual 
meta normative space in literary works and also have an amazing function in representing and expressing the writer's imagery and performing abstract things in form of live, dynamic and tangible scenes.

\section{Conclusion}

The main result of this query is that, Amir Khosro Dehlavi is one of poets that has exhibited his emotions and internal intuitions through sonant and imagery language of his lyrics. Most of his poetry is under the influence of India's atmosphere and have less imitation however composing imitative lyrics has been of accepted features of literature at that time. Amir Khosro has created new concepts and contents. However, we can count him as an innovative poet in creating imageries through diverse linguistic structures, but a lot of the imagery that are used in his poetry can be found in other Farsi poems like Sadi and Nezami, in which he has expressed little transformations in text and construction.

\section{References}

Ahmadi, Babak. 1991. Construction and Paraphrase of Text. Two volumes. First edition. Tehran, Markaz.

Jarjaani, Abdolghaaher. 1991. Secrets of Rhetoric. Translated by Jalil Tajlil. Tehran. Tehran University Press.

Dehlavi, Amir Khosro. 1964. Complete Treasury. By Darvish, M. Tehran. Javidan Express.

Shafiee Kadkani, Mohamad Reza. 1996. Music of Poetry. Tehran. Agaah Press.

Shamisa, Sirous. 2002. Meaning and Expression. Tehran. Payam Noor University Press 